\title{
Perimenopausal and Postmenopausal Health
}

\author{
Angela M Cheung*1, Ruhee Chaudhry², Moira Kapral ${ }^{3}$, Cynthia Jackevicius ${ }^{4}$ \\ and Gail Robinson ${ }^{5}$
}

\author{
Address: ${ }^{1}$ University Health Network Women's Health Program, University of Toronto, 657 University Ave, Toronto, Canada, ${ }^{2}$ University Health \\ Network Women's Health Program, University of Toronto, 657 University Ave, Toronto, Canada, ${ }^{3}$ University Health Network Women's Health \\ Program, University of Toronto, 657 University Ave, Toronto, Canada, ${ }^{4}$ University Health Network Women's Health Program, University of \\ Toronto, 657 University Ave, Toronto, Canada and ${ }^{5}$ Department of Psychiatry, University of Toronto, 21 King's College Circle, Toronto, Canada \\ Email: Angela M Cheung* - Angela.cheung@uhn.on.ca; Ruhee Chaudhry - Ruhee.Chaudhry@utoronto.ca; \\ Moira Kapral - moira.kapral@uhn.on.ca; Cynthia Jackevicius - cynthia.jackevicius@uhn.on.ca; Gail Robinson - gail.robinson@uhn.on.ca \\ * Corresponding author
}

from Women's Health Surveillance Report

Published: 25 August 2004

BMC Women's Health 2004, 4(Suppl I):S23 doi:10.II86/1472-6874-4-SI-S23

This article is available from: http://www.biomedcentral.com/I472-6874/4/SI/S23

\begin{abstract}
Health Issue: The average age of natural menopause in Western societies is estimated to be $5 \mathrm{I}$ years; women in Canada can therefore expect to live, on average, a third of their lives in postmenopausal years. During these years women are at increased risk of chronic diseases such as osteoporosis and cardiovascular disease.

Key Findings: Clinical and epidemiological data on women in perimenopause are limited. There are no adequate Canadian data on symptom severity and prevalence among perimenopausal and postmenopausal women. Scientific evidence is lacking to support or refute claims that commonly used botanical products can offer therapeutic relief of menopausal symptoms.

Recent data from the Women's Health Initiative suggest that combined estrogen plus therapy increases the risk of stroke, coronary artery disease and breast cancer. Hormone therapy is no longer recommended for the prevention of chronic diseases for asymptomatic women. Stroke is an important issue for perimenopausal and postmenopausal women and sex differences may exist in the progestin treatment of stroke. Osteoporosis affects an estimated one in six women over the age of 50 .

Data Gaps and Recommendations: There is a need to conduct clinical and epidemiological research aimed at better understanding the menopausal transition and defining its clinical phases. Investigations aimed at alternative combinations and doses of hormone therapy and nonpharmaceutical alternatives in light of known risks and benefits are also necessary. Health care practitioners and women need to be educated on the risks and effective treatment related to cardiovascular disease so they can present for treatment more quickly and receive the most effective therapies.
\end{abstract}

\section{Background}

The perimenopausal phase of a woman's life can span several years. The changes that occur during this period of transition will affect women to varying degrees. For some women these changes can give rise to symptoms that are severe and disruptive, and for others symptoms are mild and the transition is welcomed. Clinical and epidemiological data on women in perimenopause are limited, and 
what data there are come primarily from Caucasian populations. Somewhat greater attention has been given to post-menopausal women's health, and these data are often extrapolated to women in perimenopause. The average age of natural menopause in Western societies is estimated to be 51 years; women in Canada can therefore expect to live, on average, a third of their lives in postmenopausal years. During these years women are at increased risk of chronic diseases such as osteoporosis and cardiovascular disease.

\section{Methods}

Menopause touches on a number of health issues, which are addressed separately in this chapter. For some of them new data were analyzed, and for others a review of the current knowledge is presented, in part because of the lack of menopause data in large, national surveys. Literature reviews were conducted through several databases, including MEDLINE, PREMEDLINE, PsycINFO, and EMBASE. Meta-analyses of studies published in languages other than English were included. In the case of alternative therapies, a search was done for on-line resources housed at national and international health organization web sites.

For stroke, mortality data were obtained from the Canadian Mortality Database at Health Canada on individuals aged 20 and older for whom stroke was listed as the underlying cause of death (ICD codes 431, 434, 436). Rates were age-standardized to the 1991 Canadian population. Hospital admission rates for stroke were obtained from the Canadian Morbidity Database at the Canadian Institute for Health Information. Cases were included if they were treated at an acute care hospital and had a diagnosis of stroke (ICD-9 codes 431, 434, 436). Subsequent admissions in the time period could not be identified and were not excluded. Geographic breakdowns reflect the province of hospitalization.

Information on cardiovascular disease has been supplemented by data from the FASTRAK ${ }^{\circledR}$ II clinical registry, which collects quantitative and qualitative data on demographic characteristics, treatments and outcomes of all patients with acute coronary syndrome during their stay at participating Canadian hospitals. The registry includes all cardiac patients to minimize patient selection and was specifically designed to include hospitals without a tradition of participating in clinical trials in an effort to minimize hospital selection. In addition, clinical data elements are captured. Data are processed at the FASTRAK $^{\circledR}$ II Data Management Centre, based in the Cardiology Department of a major teaching hospital. These data were used to demonstrate practice patterns for reperfusion therapies in this setting. All female patients in the registry who had an ST elevation myocardial infarction during the period January 1, 2001, to December 31, 2001, were included. Data on 1,489 female patients were available for analysis

\section{Results \\ Perimenopause}

Natural menopause is defined as the permanent cessation of menstruation resulting from the loss of ovarian follicular activity. It is confirmed after 12 consecutive months of amenorrhea in the absence of other pathological or physiological causes, given that a woman who has experienced 12 months without flow has a $5 \%$ or lower chance of further flow.[1] Natural menopause, by this definition, can be known with certainty only in retrospect. There is currently no single biological marker to identify when a woman has reached menopause.[2] Perimenopause is defined by the World Health Organization and the North American Menopause Society as the two to eight years preceding menopause and one year following final menses.[1,3]

The average age at menopause is 51 years for Caucasian women in Western societies. Studies have reported differences in age at menopause (earlier or later) by race or country, but findings are not consistent. Studies in developing countries generally report younger age at menopause, but this is likely due to methodological differences. Factors that may affect age of menopause are not well understood, although smoking has been consistently related to earlier age at menopause by one to two years.

There is a great deal that is yet to be understood about perimenopause and women's experiences of this period of transition. Studies of menopausal symptoms are problematic, given that it is difficult to accurately identify when women enter the perimenopausal phase. Temporal associations between menopause and what may be menopausal symptoms cannot be assessed using cross-sectional studies. There have been a few good longitudinal studies that have looked at the perimenopausal transition, [4-7] including one in Manitoba. National data on symptom prevalence are not available.

A majority of women will experience menstrual changes years before their final period. Only an estimated 10\% report an abrupt cessation. Heavy flow is common and, among women in the Manitoba study, led to medical consultation by about $25 \%$ of women. [6] Some women experience acute perimenopausal symptoms. The most commonly reported are vasomotor symptoms (hot flushes and night sweats), vaginal dryness, mastalgia, sleep disturbances, urinary incontinence, changes in libido, mood changes and fatigue. The prevalence of many of these symptoms varies from early to late perimenopause. Vasomotor symptoms, though they are not 
unique to menopause, are by far the most commonly reported. In studies of Caucasian populations, up to $85 \%$ of Caucasian women report vasomotor symptoms, and these women are more likely to report other physical and emotional symptoms. There is great variation among countries in the proportion of women reporting hot flushes. Estimates within countries also vary widely. Studies of Asian populations tend to report the lowest rates.[8] Studies in Thailand and Japan have reported rates of $6 \%$ and $12 \%$ respectively, and studies in Africa have reported rates of $30 \%$ to $80 \%$.[8] Truly comparable studies in nonCaucasian populations are lacking.

There is some debate as to which of these symptoms can be attributed directly to hormonal fluctuations and which cannot. Short-term hormone therapy, traditionally used for the management of menopausal symptoms, has been shown to be more effective than placebo only in the treatment of vasomotor symptoms, sleep disturbances and genitourinary symptoms. $[9,10]$ The experience of other symptoms requires further attention.

\section{Psychiatric Disorders in Perimenopause and Menopause}

Contrary to widely held beliefs, menopause is not associated with an increase in psychiatric disorders, although the perimenopausal period may be. In one of the first studies of menopausal symptomology, Neugarten and Kraines found an increase in somatic but not in psychological complaints at menopause.[11] Multiple community studies have since indicated no increase in the prevalence of psychiatric disorders after menopause.[6,12-16] On the other hand, some studies do suggest a higher prevalence of psychiatric morbidity among perimenopausal women, especially those seeking care in menopause clinics. $[17,18]$ Studies have found no relation between menopausal status and symptoms such as insomnia, fatigue and depression, although they have noted an increase in somatic symptoms at menopause. $[11,19]$ There does, however, seem to be an increase in psychiatric symptoms, including depression, anxiety and psychosomatic symptoms, in the years immediately preceding the complete cessation of menses.[20] A prior history of depression has been noted to be associated with depressive and other psychological symptoms in perimenopause.[21]

Women who become depressed during the perimenopause may be reacting to one or a combination of factors. Alterations in the levels of reproductive hormones may directly affect central neurotransmitter activity and contribute to a dysregulation of the hypothalamic-pituitaryadrenal axes, leading to the onset of depression in vulnerable women.[13] Women with histories of depression, especially occurring at times of hormonal change such as premenstrually or postpartum, may be particularly vul- nerable. $[16,22,23]$ For some women, the hormone-sensitive physical complaints such as night sweats and hot flushes result in discomfort, irritability and low selfesteem that can be confused with major depressive disorders. Psychosocial stressors may also play a role. Changes in family roles, loss of fertility and fear of aging with its ensuing loss of physical attractiveness, usefulness and status in the community can lead to depression.[24] Lifestyle issues such as smoking and stress also appear to be related to symptoms of depression.[14,25]

For menopausal women experiencing mild depression as well as anxiety, insomnia and vasomotor symptoms, ovarian hormone therapy is a first-line treatment unless there are contraindications to estrogen use.[26] Amelioration of the physical symptoms may lead to an increase in wellbeing. In women with moderate to severe depression or anxiety, antidepressant medication is the treatment of choice and the use of estrogen in such cases remains controversial.[27,28] Studies using estrogen to treat major depression have yielded mixed results.[29,30] The use of unopposed estrogen is contraindicated in women with intact uteruses. The addition of progesterone has been associated with a worsening of mood.[29,31] The role of ovarian hormone therapy in augmenting the effects of antidepressants is still unclear.[32,33]

More research is needed to clarify the effects of using hormones in the treatment of menopausal women. Educational programs are also important to give correct information to perimenopausal women and debunk myths that may contribute to depression and low selfesteem at this time of life.[24,34] Women should be directed to some of the Web sites that provide womencentred lay information in order to further reduce their fears and misconceptions about the menopause. These include the Web sites for Menstrual Cycle Research http:/ /www.pop.psu.edu/smcr, National Women's Health Network http://www.nwhn.org/, Dr. Susan Love http:// www.susanlove.com/community flash A frames.html, and the Centre for Menstrual Cycle and Ovulation Research http://www.cemcor.ubc.ca.

\section{Alternative Therapies}

For a variety of reasons, women appear to be taking a greater interest in alternative therapies for treatment of menopausal symptoms. Despite what appears to be an increasing prevalence in use among Canadian women, very little has been published with respect to efficacy, side effects or the pharmacokinetic features of botanical products.

With the exception of black cohosh, scientific evidence is lacking about whether commonly used botanical products are effective for the treatment of menopausal symp- 
toms. Red clover (Trifolium pratense) is a source of a large number of phytoestrogens (isoflavones) and has shown estrogenic activity in a number of studies; however, it has not been shown to decrease symptoms significantly more then placebo. Chasteberry (Vitex agnus-castus), dong quai (Angelica sinensis), Asian ginseng (Panax ginseng), North American ginseng (Panax quinquefolius), licorice (Glycyrrhiza glabra) and evening primrose (Oenothera biennis) are also used for the management of menopausal symptoms, but without evidence of their effectiveness. Studies have shown chasteberry to be effective in treating mastalgia and premenstrual syndrome.

A number of clinical trials, mostly German, have found that black cohosh (Cimicifuga racemosa) relieves perimenopausal symptoms, including hot flushes and depressed mood. Black cohosh may decrease hot flushes by $25 \%$ as compared with placebo.[35]. It has been approved for use in Germany by the Special Expert Committee of the German Federal Institute for Drugs and Medical Devices (Commission E). Phase I and phase II clinical trials are currently under way in the United States.

Many of the studies reported in the literature have been of short duration. Often an effect is observed but is similar to that seen for placebo over the short period of follow-up. It is not clear whether this relation would hold true over a longer period. Recent studies have found estrogenic activity in a number of botanical products commonly used for the treatment of menopausal symptoms, suggesting a potential for their use and a viable mechanism of action.[36]

Soy products, rich in phytoestrogens (isoflavones), have the potential to provide an exogenous source of estrogen, and the lower rates of vasomotor symptoms reported in Asian populations are sometimes attributed to greater soy intake. Data from studies considering the relation of soy, or isoflavones, to vasomotor symptoms are inconclusive. Studies in post-menopausal women, however, have shown a favourable effect on lipid levels.[2,36]

Other alternative therapies for which there is some evidence to suggest a decrease in vasomotor symptoms include relaxation, mind-body or yoga breathing strategies.[37,38] As well, topical or transdermal use of progesterone was shown in a controlled trial to decrease vasomotor symptoms in menopausal women.[39]

\section{Hormone Therapy}

Hormone therapy (HT), or what has been known as hormone replacement therapy (HRT), is a term that describes a variety of regimens involving different estrogens and progestins. Those involving only estrogen therapy are mainly used for women without a uterus, and those involving a combination of estrogen plus progestin are for those with a uterus, since unopposed estrogen (or estrogen alone) increases the risk of endometrial cancer.[40] HT has been used for decades in the treatment of hot flushes and vaginal dryness. Over the past decade, there has been significant interest in its use for long-term prevention of chronic diseases, such as cardiovascular disease, cancer, osteoporosis and memory loss. Observational studies examining long-term hormone use have noted a slight increase in incidence of breast cancer among hormone users compared with non-users and a decrease in cardiovascular disease.[41] However, recent results from the Women's Health Initiative show an increase in both cardiovascular disease and breast cancer.[42] The reason for the differences in these findings requires further exploration.

The Women's Health Initiative (WHI) is a multi-centre, randomized trial across the United States examining a variety of factors that may affect post-menopausal health. It is the most expensive study funded by the National Institutes of Health in its history and involves 160,000 post-menopausal women.[5] One arm of this study was a randomized, double-blind placebo-controlled trial involving 16,608 post-menopausal women, which examined the use of combined estrogen plus progestin taken orally every day, as compared with placebo.[42] The study was terminated early because the risks outweighed the benefits. After an average of 5.2 years of follow-up, there was a $26 \%$ increase in breast cancer, a $29 \%$ increase in coronary heart disease and a $41 \%$ increase in stroke among hormone users. There was, however, a 34\% decrease in hip fractures and a $37 \%$ decrease in colorectal cancers.

In light of these results, many scientific bodies (including the Society of Obstetricians and Gynaecologists of Canada, [43] the American College of Obstetricians and Gynecologists,[44] the North American Menopause Society, [45] the U.S. Preventive Services Task Force[46] and the Canadian Task Force on Preventive Health Care [47]) decided that HT, especially taken in this regimen, does not fit the profile of a compound for the prevention of diseases and have thus changed their recommendations. All are recommending that use of HT in post-menopausal women should be limited to the treatment of perimenopausal symptoms, the dose should be as low as possible, the duration should be as short as possible, and the use of HT should be evaluated periodically by the woman and her health care provider. These scientific bodies are also recommending against using HT for the prevention of cardiovascular diseases or as firstline therapy for the prevention and treatment of osteoporosis in asymptomatic women. The Food and Drug Administration in the United States has recently instituted a policy to include these warnings on all HT 
packaging, whether it is oral or transdermal, estrogen only or combined estrogen plus progestin.

Despite being the largest trial on HT to date, many questions remain unanswered. The issue of whether estrogen alone has similar effects will be addressed by an arm of the WHI that is continuing and involves 10,000 post-menopausal women. However, the trial results so far have made research on the use of HT for long-term prevention of chronic diseases much more difficult to conduct. Two further analyses were published recently from the WHI showing no difference in cognition with estrogen plus progestin therapy, [48] and if anything, HT may increase the risk of dementia in women 65 and over.[49] Furthermore, another analysis showed HT made no difference in quality of life in women without vasomotor symptoms.[50] These findings, coupled with previously reported WHI data, support the conclusion that the risks of estrogen plus progestin outweigh the benefits.

\section{Osteoporosis}

Osteoporosis affects an estimated one in six women and one in sixteen men over the age of 50.[51] Risk factors are similar for men and women, but women experience a higher incidence of fracture, likely because of a higher prevalence of risk factors. Post-menopausal women in particular are at increased risk. In the first five years immediately after menopause, women can experience bone loss at a rate of $2 \%$ to $5 \%$ per year. This rate of bone loss usually diminishes after about ten years, to $1 \%$ to $2 \%$ per year.

The most significant implications associated with osteoporosis are complications from fragility fractures. Osteoporosis is asymptomatic until a fracture occurs. Osteoporotic fractures, particularly of the hip and spine, cause considerable morbidity and mortality. For an average 50-year-old woman, the lifetime risk of a forearm fracture is $16 \%$, of a spine fracture is $15.6 \%$, of a hip fracture is $17.5 \%$ and of any osteoporotic fracture is more than 40\%.[52] Fractures can lead to chronic pain and spinal deformity. As many as $20 \%$ of hip fracture patients will die in their first year after the fracture, often because of complications due to hospitalization[53]. Many will lose their independence and require long-term care. Men show higher rates of mortality than women following hip fracture. Whether the decrease in survival can be attributed to fractures or to comorbid illnesses is controversial.

Risk factors for osteoporotic fracture include a prior osteoporotic fracture, increasing age, low bone mineral density (BMD) and a family history of osteoporotic fracture. Other factors that may also contribute to fracture risk but may be correlated with $\mathrm{BMD}$ include low body weight
(BMI < 20-25 kg/m2), high caffeine intake, smoking, low physical activity and low calcium intake.

A relation between $\mathrm{BMD}$ and fracture risk has been observed in a number of studies, and BMD remains the best quantifiable skeletal predictor of osteoporotic fracture for those who have not had a fragility fracture. The standard classification for osteoporosis and osteopenia is based on the 1993 WHO criteria,[54] which compare $\mathrm{BMD}$ to a reference population of post-menopausal Caucasian women. Using the WHO criteria, a BMD value greater than or equal to 2.5 standard deviations below the young adult mean is defined as osteoporosis, and a BMD value between 1 and 2.5 standard deviations below is defined as osteopenia. Women with osteopenia have a lower risk of fracture than women with osteoporosis, but they may be at greater risk than women with normal bone mineral density. The Canadian Multicentre Osteoporosis Study estimates the prevalence of osteoporosis to be $15.8 \%$ among women and $6.6 \%$ among men over the age of 50.[51] The prevalence of osteopenia among women aged 50 and over in Canada is 45.9\%.[51] This is very similar to the $50 \%$ prevalence rate observed in the National Health and Nutrition Examination Survey III study in the United States.

Because osteoporotic fractures often result in loss of independence and decreased quality of life, the burden they place on women, their social supports and the health care system is substantial. An understanding of factors that contribute to fractures and strategies to prevent falls are important, especially in decreasing hip fractures among the elderly. Prevention and treatment can be started early in women at high risk of fracture. Preventive strategies currently include lifestyle modifications; ensuring adequate dietary calcium and vitamin D intake; and several pharmacological treatment options, including bisphosphonates, selective estrogen receptor modulators and, in selected cases, parathyroid hormone, calcitonin and HT. Weight-bearing exercise can increase peak bone mass in teenagers and help maintain bone mass in post-menopausal women.

\section{Stroke}

Stroke is the fourth leading cause of death and a leading cause of disability in Canadian women.[55,56] Major risk factors for stroke include atrial fibrillation, hypertension, diabetes mellitus, smoking and hyperlipidemia. The prevalence of risk factors for stroke is similar among women and men, although women over the age of 45 are more likely to have a diagnosis of hypertension.[56] Smoking is more common among men than women in every age group except those under 20 years.[56] 
Stroke admissions, mortality and length of stay were calculated for Canadian women and men using data from the Canadian Institute for Health Information and ICD-9 codes 431, 434 and 436. In 2000, overall hospitalization rates for stroke were lower among women than men (713 versus 955 per 100,000), but in the older age groups were higher among women (2,038 women versus 1,942 men per 100,000 aged over 75). In addition, since stroke risks increase with age and since women are overrepresented in the older age groups, the actual number of women with stroke is higher than the number of men. In Canada in 2000, for example, there were 10,592 women admitted with stroke, compared with 9,816 men. There were some variations in stroke admission rates across the country (Figure 1).

Stroke mortality rates in Canada tend to be lower among women than men in every age group. In 1997, for example, for people aged 65 to 74 years, the mortality rate from cerebral infarction was 55.69/100,000 among women as compared with 95.87/100,000 among men. However, because of the greater proportion of women in the older age groups, in which stroke mortality is highest, stroke accounts for more deaths in women than in men $(9,375$ women versus 6,673 men in 1997) and a higher proportion of all deaths (9\% among women versus 5.9\% among men).[56] Stroke mortality rates vary across Canada (Figures 2 and 3 ).

Women who experience stroke are often widowed, are less likely to have social supports, and are more likely to be discharged to long-term care facilities after stroke.[57] Stroke admissions tend to be longer and more costly for women than for men $(\$ 32,000$ versus $\$ 23,000$ per admission).[57]

Secondary stroke prevention includes antiplatelet agents, anticoagulants for atrial fibrillation, and carotid endarterectomy for carotid stenosis. Canadian data suggest that sex differences exist in the secondary prevention of stroke. For example, older women (aged over 85) are less likely than men to be prescribed antiplatelet agents. [58] In addition, Canadian women are about half as likely as men to undergo carotid endarterectomy, even after adjustment for age.[57,59]

\section{Cardiovascular Disease}

Cardiovascular disease (CVD) is the leading cause of death in Canadian women.[55,56] In general, major risk factors for CVD include hypertension, dyslipidemia, diabetes mellitus, smoking, inactivity, male sex and older age. According to the National Population Health Survey 1996-1997 analyses published in The Changing Face of Heart Disease and Stroke in Canada (2000),[56] many of the major risk factors have similar prevalence among men and women. However, more women are likely to have hypertension, and more men than women are likely to have diabetes mellitus and to be smokers.

While CVD has been well accepted as a prominent condition in men, there has been some controversy about the signs and symptoms, diagnosis and treatment of CVD in women. It is under-appreciated that women may present with a broader range of signs and symptoms of heart disease than men. $[60,61]$ Sex differences have been found in the management of CVD. Physicians pursue a less aggressive management approach to CVD for women, who receive fewer referrals for diagnostic and revascularization procedures and are under-treated with effective medications. [62-66]

Preferential prescribing for males has also been uncovered for evidence-based therapies, Canada and the United States showing similar patterns. In a cohort of 2,070 postmyocardial infarction (MI) patients from Alberta and Nova Scotia followed from 1987 to 1992, women not only had a significantly lower rate of prescription for Aspirin (69\% versus $79 \%$ ), beta-blockers (36\% versus $48 \%$ ) and thrombolytic agents (20\% versus $30 \%)$, but also a higher mortality rate than their male counterparts (18\% versus 12\%).[67] Several other studies in North America throughout the 1990s support these findings of differential prescribing according to sex in the treatment of cardiovascular disease. [68-71]

This is of particular concern, since the beneficial effects of therapy for acute coronary syndromes - such as fibrinolytics, acetylsalicylic acid (ASA), beta-blockers and angiotensin-converting enzyme inhibitors - appear to be equally effective in women as in men. [72-74] Many of these studies includeonly about $25 \%$ of women as participants, but the benefits of therapy are of a similar magnitudeas in men.

More recently, Haddad and colleagues studied a small group of $717 \mathrm{MI}$ patients in Nova Scotia to assess their medical management and found that there were few differences in prescribing patterns between men and women.[75] Previous sex differences may be decreasing, but ineffective or potentially harmful therapies are still being preferentially given to women. Most recently, the Institute for Clinical Evaluative Sciences (ICES) in Ontario assessed the use of medication in older post-MI patients (65+ years) over the period of 1994-1995 to 1996-1997 and found few sex-related differences in treatment rates.[76] Overall, there was room for improvement in the use of evidence-based therapies in both sexes. However, there was a $4 \%$ to $5 \%$ higher rate of use of calcium channel blockers among women aged 65 to 74 and 75 to 84 years as compared with men. This class of drug has not 


\begin{tabular}{|c|c|c|c|c|c|c|}
\hline \multirow[b]{3}{*}{ Province/Territory } & \multicolumn{6}{|c|}{ Women } \\
\hline & \multicolumn{2}{|c|}{$50-64$} & \multicolumn{2}{|c|}{$65-74$} & \multicolumn{2}{|c|}{$75+$} \\
\hline & $\mathbf{n}$ & Rate & $\mathbf{n}$ & Rate & $\mathbf{n}$ & Rate \\
\hline Y.T. & * & .* & * & * & 6 & 0.04225 \\
\hline N.W.T. & * & * & • & • & .* & *. \\
\hline Nun. & $\cdot$ & $\cdot$ & $*$ & * & $\cdot$ & $\cdot$ \\
\hline P.E.I. & 8 & 0.0054 & 20 & 0.01781 & 70 & 0.03062 \\
\hline N.L. & 23 & 0.00454 & 44 & 0.01094 & 111 & 0.01964 \\
\hline N.B. & 24 & 0.00282 & 44 & 0.00621 & 179 & 0.01485 \\
\hline N.S. & 25 & 0.00309 & 51 & 0.00733 & 224 & 0.01835 \\
\hline Alta. & 61 & 0.00286 & 117 & 0.00689 & 443 & 0.01467 \\
\hline Sask. & 37 & 0.00412 & 74 & 0.00851 & 292 & 0.01617 \\
\hline Man. & 44 & 0.00501 & 93 & 0.01166 & 352 & 0.01993 \\
\hline Ont. & 385 & 0.00495 & 770 & 0.01101 & 2506 & 0.02116 \\
\hline Que. & 353 & 0.00629 & 658 & 0.01315 & 1914 & 0.02438 \\
\hline B.C. & 114 & 0.0039 & 224 & 0.00923 & 809 & 0.01832 \\
\hline Canada & 1082 & 0.00475 & 2117 & 0.01064 & 6993 & 0.02038 \\
\hline
\end{tabular}

\begin{tabular}{|c|c|c|c|c|c|c|}
\hline \multirow[b]{3}{*}{ Province/Territory } & \multicolumn{6}{|c|}{ Men } \\
\hline & \multicolumn{2}{|c|}{$50-64$} & \multicolumn{2}{|c|}{$65-74$} & \multicolumn{2}{|c|}{$75+$} \\
\hline & n & Rate & $\mathbf{n}$ & Rate & n & Rate \\
\hline Y.T. & $*$ & $*$ & $*$ & $*$ & $*$ & $*$ \\
\hline N.W.T. & $*$ & .* & $*$ & $*$ & . & *. \\
\hline Nun. & * & * & - & - & $*$ & $*$ \\
\hline P.E.I. & 18 & 0.01114 & 23 & 0.01699 & 39 & 0.02203 \\
\hline N.L. & 61 & 0.01071 & 64 & 0.01306 & 103 & 0.02071 \\
\hline N.B. & 54 & 0.00576 & 66 & 0.00855 & 105 & 0.01132 \\
\hline N.S. & 37 & 0.0041 & 77 & 0.0099 & 143 & 0.01525 \\
\hline Alta. & 95 & 0.00425 & 165 & 0.00817 & 287 & 0.01216 \\
\hline Sask. & 39 & 0.00422 & 99 & 0.01 & 238 & 0.01582 \\
\hline Man. & 52 & 0.00567 & 127 & 0.01397 & 234 & 0.01767 \\
\hline Ont. & 617 & 0.00725 & 939 & 0.01152 & 1741 & 0.01938 \\
\hline Que. & 573 & 0.00888 & 908 & 0.0157 & 1230 & 0.02184 \\
\hline B.C. & 176 & 0.0056 & 300 & 0.01034 & 594 & 0.01648 \\
\hline Canada & 1749 & 0.00697 & 2800 & 0.1209 & 4764 & 0.01817 \\
\hline
\end{tabular}

\section{Figure I}

Age and Sex-Specific Stroke Admission Rates in Canada by Province and Territory, 2000-200 I. Source: Canadian Institute for Health Information, Hospital Morbidity Database 


\begin{tabular}{|c|c|c|c|c|c|c|}
\hline \multirow[b]{3}{*}{ Province/Territory } & \multicolumn{6}{|c|}{ Women } \\
\hline & \multicolumn{2}{|c|}{$50-64$} & \multicolumn{2}{|c|}{$65-74$} & \multicolumn{2}{|c|}{$75+$} \\
\hline & $\mathbf{n}$ & Rate & $\mathbf{n}$ & Rate & $\mathbf{n}$ & Rate \\
\hline Y.T. & $\cdot$ & $*$ & . & ** & $\cdot$ & $*$ \\
\hline N.W.T./Nun. & • & .* & • & *. & • & . \\
\hline N.L. & * & * & • & * & • & *. \\
\hline P.E.I. & - & $*$ & - & * & - & *. \\
\hline N.S. & • & 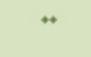 & 10 & 28.04 & 22 & 57.75 \\
\hline N.B. & • & $\ddot{*}$ & 9 & 30.65 & 12 & 42.38 \\
\hline Que. & 33 & 5.74 & 59 & 19.72 & 182 & 73.45 \\
\hline Ont. & 50 & 5.89 & 80 & 17.83 & 190 & 49.41 \\
\hline Man. & 7 & 9.04 & 5 & 11.23 & 27 & 55.61 \\
\hline Sask. & * & *. & 6 & 13.92 & 21 & 42.35 \\
\hline Alta. & 10 & 5.81 & 10 & 11.35 & 38 & 50.04 \\
\hline B.C. & 15 & 5.21 & 23 & 15.59 & 65 & 45.39 \\
\hline Canada & 122 & 5.52 & 207 & 17.84 & 563 & 54.26 \\
\hline
\end{tabular}

\begin{tabular}{|c|c|c|c|c|c|c|}
\hline \multirow[b]{3}{*}{ Province/Territory } & \multicolumn{6}{|c|}{ Men } \\
\hline & \multicolumn{2}{|c|}{$50-64$} & \multicolumn{2}{|c|}{$65-74$} & \multicolumn{2}{|c|}{$75+$} \\
\hline & $\mathbf{n}$ & Rate & $\mathbf{n}$ & Rate & $\mathbf{n}$ & Rate \\
\hline Y.T. & * & $*$ & $\cdot$ & "* & * & $*$ \\
\hline N.W.T./Nun. & - & .. & - & .. & - & •. \\
\hline N.L. & - & .. & - & •. & 8 & 74.36 \\
\hline P.E.I. & * & .* & * & .* & * & " \\
\hline N.S. & - & * & 9 & 29.62 & 7 & 34.23 \\
\hline N.B. & • & .* & 9 & 36.25 & 9 & 54.02 \\
\hline Que. & 40 & 7.67 & 80 & 32.96 & 120 & 95.50 \\
\hline Ont. & 60 & 7.57 & 83 & 21.60 & 149 & 69.26 \\
\hline Man. & 6 & 8.25 & 10 & 26.95 & 28 & 99.95 \\
\hline Sask. & 5 & 7.99 & 10 & 27.68 & 16 & 55.95 \\
\hline Alta. & 9 & 5.06 & 17 & 21.39 & 36 & 77.53 \\
\hline B.C. & 20 & 6.98 & 41 & 29.94 & 47 & 53.23 \\
\hline Canada & $|5|$ & 7.22 & 262 & 26.34 & 420 & 71.53 \\
\hline
\end{tabular}

\section{Figure 2}

Age and Sex-Specific Intracerebral Haemorrhage Mortality Rates per 100,000 in Canada by Province and Territory, 1997-1998 Source: Health Canada, Canadian Mortality Database 


\begin{tabular}{|c|c|c|c|c|c|c|}
\hline \multirow[b]{3}{*}{ Province/Territory } & \multicolumn{6}{|c|}{ Women } \\
\hline & \multicolumn{2}{|c|}{$50-64$} & \multicolumn{2}{|c|}{$65-74$} & \multicolumn{2}{|c|}{$75+$} \\
\hline & n & Rate & $\mathbf{n}$ & Rate & $\mathbf{n}$ & Rate \\
\hline Y.T. & $\cdot$ & $\cdot$ & $\cdot$ & $\cdot$ & $\cdot$ & "* \\
\hline N.W.T./Nun. & • & • & - & . & - & .. \\
\hline N.L. & • & • & 16 & 86.27 & 112 & 663.15 \\
\hline P.E.I. & • & - & • & - & 36 & 575.78 \\
\hline N.S. & 8 & 12.03 & 23 & 62.73 & 205 & 502.82 \\
\hline N.B. & - & • & 19 & 65.91 & 188 & 610.94 \\
\hline Que. & 27 & 4.79 & 145 & 47.47 & 1078 & 418.56 \\
\hline Ont. & 54 & 6.71 & 273 & 59.76 & 1983 & 495.48 \\
\hline Man. & 9 & 12.59 & 34 & 71.46 & 298 & 574.19 \\
\hline Sask. & • & • & 16 & 37.32 & 284 & 554.30 \\
\hline Alta. & 9 & 5.02 & 33 & 37.46 & 404 & 504.02 \\
\hline B.C. & 19 & 7.02 & 100 & 63.52 & 899 & 609.43 \\
\hline Canada & 136 & 6.43 & 664 & 55.88 & 5492 & 506.61 \\
\hline
\end{tabular}

\begin{tabular}{|c|c|c|c|c|c|c|}
\hline \multirow[b]{3}{*}{ Province/Territory } & \multicolumn{6}{|c|}{ Men } \\
\hline & \multicolumn{2}{|c|}{$50-64$} & \multicolumn{2}{|c|}{$65-74$} & \multicolumn{2}{|c|}{$75+$} \\
\hline & $\mathbf{n}$ & Rate & $\mathbf{n}$ & Rate & $\mathbf{n}$ & Rate \\
\hline Y.T. & • & .* & - & ." & $\cdot$ & ". \\
\hline N.W.T./Nun. & • & $*$ & • & •• & • & * \\
\hline N.L. & 7 & 18.78 & 17 & 100.26 & 66 & 657.80 \\
\hline P.E.I. & - & 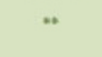 & 10 & 223.28 & 22 & 695.42 \\
\hline N.S. & 11 & 16.91 & 36 & 118.32 & 105 & 536.67 \\
\hline N.B. & • & * & 29 & 119.02 & 88 & 549.54 \\
\hline Que. & 54 & 10.41 & 170 & 70.01 & 540 & 449.07 \\
\hline Ont. & 87 & 11.19 & 276 & 71.98 & 1128 & 545.79 \\
\hline Man. & 13 & 17.57 & 33 & 86.20 & 183 & 659.73 \\
\hline Sask. & 6 & 9.25 & 40 & 108.40 & 177 & 601.28 \\
\hline Alta. & 20 & 11.28 & 51 & 64.20 & 242 & 541.53 \\
\hline B.C. & 24 & 8.29 & 113 & 82.31 & 505 & 596.76 \\
\hline Canada & 228 & 11.03 & 776 & 77.89 & 3058 & 543.43 \\
\hline
\end{tabular}

\section{Figure 3}

Age and Sex-Specific Cerebral Infarction Mortality Rates per 100,000 in Canada by Province and Territory, I 997-I 998 Source: Health Canada, Canadian Mortality Database 
been shown to improve mortality after MI and in some case may increase mortality. In other studies, women have received more nitrates and calcium channel blockers, despite the fact that these drugs have not been shown to decrease mortality. $[77,78]$ In a study assessing whether evidence changes practice, using the uptake of the landmark $4 \mathrm{~S}$ statin trial into practice as the example, the increase in the rate of statin therapy among women was 1.6-fold lower than that among men $(p=0.006)$. This study indicates a lag in the use of evidence-based therapies - in this case, statins - in older women in Ontario.[79]

The FASTRAK II database of acute cardiac hospital admissions across Canada for the year 2001 was used to determine more recent trends by sex in the presentation of acute myocardial infarction (AMI) and use of acute therapies. There were 4,897 patients with AMI in 2001, 3,365 (69.3\%) of whom were male and 1,489 (30.7\%) of whom were female. Figure 4 summarizes the AMI data for females, and Figure 5 summarizes the data for men. Women take longer than men to present to hospital after the start of their symptoms and are more ill upon presentation (Killip class). Fewer women in the younger age groups ( $<55$ years and 55 to 64 years) appear to receive reperfusion therapy with either fibrinolysis or primary angioplasty. Fewer women in the older age groups (65 to 74 years and over 75 years) receive primary angioplasty. In all age categories, women have a longer time from arrival to receipt of fibrinolysis. The target goal of door-to-needle time of under 30 minutes is reached in $48.5 \%$ of men versus only $38.8 \%$ of women. While the numbers are small, more women than men have strokes and major bleeding, and the rate of death in hospital at 48 hours after admission is higher among women across allage categories. These data show that women present later and are more ill at presentation, are treated less often and later with fibrinolysis and angioplasty, and have more complications of their AMI and its treatment.

Sex differences in prescribing patterns for congestive heart failure have not been consistent, but they tend to be less than those found in the multitude of studies evaluating AMI.[80,81] In an ICES analysis of older patients with congestive heart failure in Ontario from 1994-1995 to 1996-1997, no sex-related differences were found in the rates of use of ACE inhibitors.[76] One Canadian study, which assessed the use of thromboembolic prophylaxis in 3,575 patients with atrial fibrillation from 12 hospitals during the period 1993-1994, found that significantly more females received ASA or no treatment as compared with men. Warfarin was the drug of choice for atrial fibrillation in this study.[82] It is possible that some elderly, frail women may have contraindications that prevent them from receiving the more effective therapy, warfarin.
Greater awareness and reduction of risk factors for cardiovascular disease in women are needed. While preventive medications are being used more frequently in women, greater use of effective therapies and less use of ineffective or potentially harmful ones are warranted.

\section{Summary of Results}

- Clinical and epidemiologic data on women in perimenopause are limited. There do not appear to be adequate Canadian data on symptom severity and prevalence among perimenopausal and post-menopausal women. Existing data on age at menopause and experience of the menopausal transition come primarily from Caucasian populations.

- Perimenopausal and post-menopausal women differ hormonally and experientially. Therapies tested on one population should not necessarily be extrapolated to the other.

- Scientific evidence is lacking to support or refute claims that commonly used botanical products can offer therapeutic relief of menopausal symptoms. There are inadequate data on the efficacy, side effects and pharmacokinetic features of these products. However, recent studies of botanical products commonly used for treatment of menopausal symptoms have demonstrated estrogenic activity, suggesting a potential for their use and a viable mechanism of action.

- Recent data from the Women's Health Initiative suggest that combination HT increases the risk of stroke, coronary artery disease and breast cancer. The study did demonstrate a decrease in risk of colon cancer and hip fracture, but no difference in cognition or quality of life in asymptomatic women. Thus, combination HT is no longer recommended for prevention of chronic diseases in asymptomatic women.

- Sex differences may exist in the secondary prevention of stroke, and there may be evidence to suggest differential prescribing for CVD according to sex.

- Stroke is an important issue for women, particularly those in the older age groups. Women may be less likely than men to receive antiplatelet agents and carotid endarterectomy for secondary stroke prevention, although further research is needed to determine whether this is due to sex alone, to age or to other clinical factors.

- Women are at greater risk of osteoporosis and osteoporotic fractures than men. However, women have lower in-hospital mortality rates than men following hip fracture. 


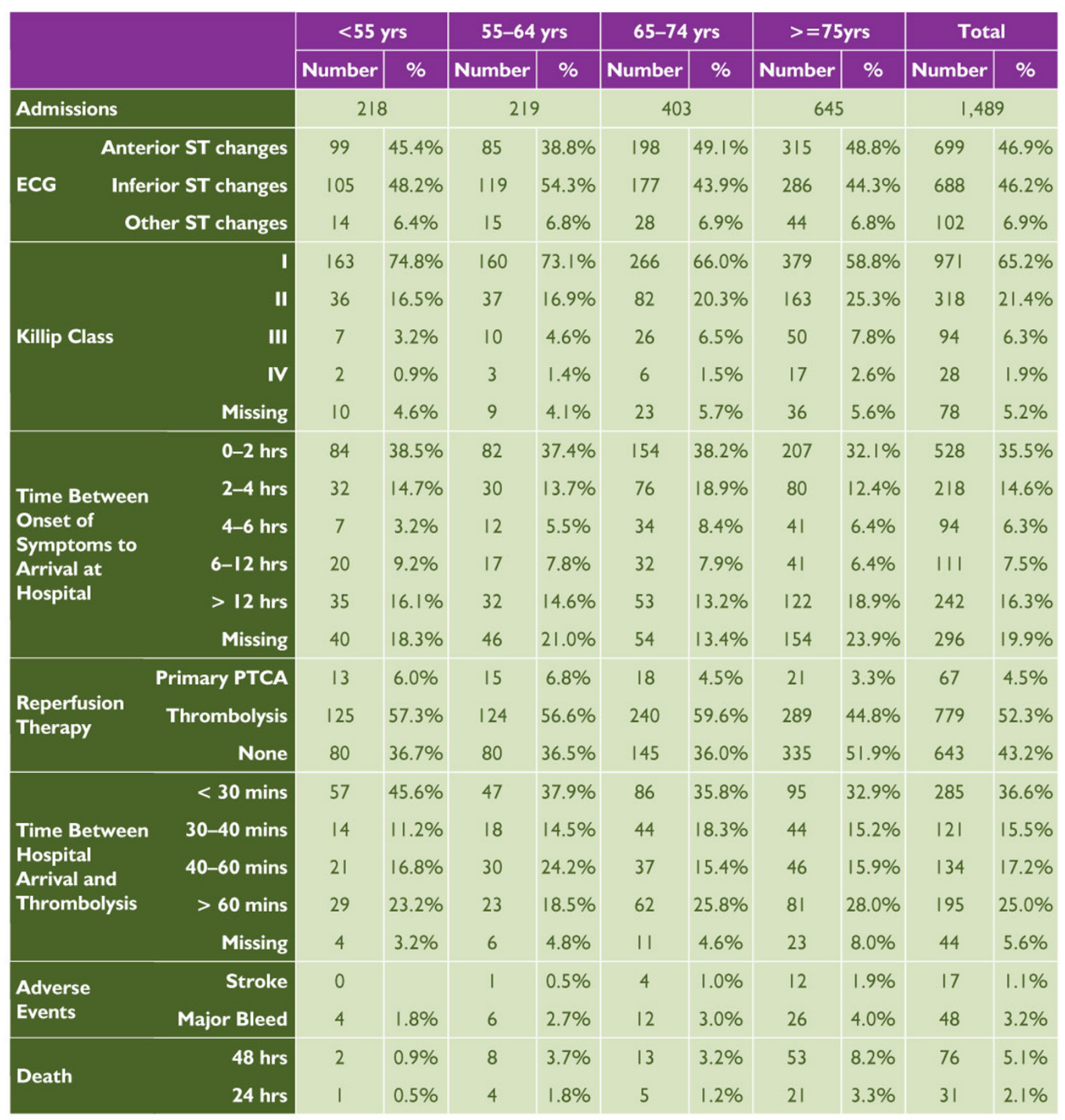

\section{Figure 4}

Use of Reperfusion Therapy in Women with ST Elevation Acute Myocardial Infarction in Canada, January I, 200 I to December 3 I, 200 I Source: FASTRAK ${ }^{\circledR}$ I I Clinical Registry, 200 I

- Psychiatric disorders are not significantly increased among menopausal women, although there is some increase in psychiatric symptoms in the perimenopause.

\section{Discussion}

\section{Recommendations}

- Conduct clinical and epidemiologic research aimed at better understanding the menopausal transition and defining its clinical phases. In order to collect data on perimenopausal women, we must be able to identify them. 


\begin{tabular}{|c|c|c|c|c|c|c|c|c|c|c|c|}
\hline & \multicolumn{2}{|c|}{$<55$ yrs } & \multicolumn{2}{|c|}{$55-64$ yrs } & \multicolumn{2}{|c|}{$65-74$ yrs } & \multicolumn{2}{|c|}{$>=75 \mathrm{yrs}$} & \multicolumn{2}{|c|}{ Total } \\
\hline & & Number & $\%$ & Number & $\%$ & Number & $\%$ & Number & $\%$ & Number & $\%$ \\
\hline \multicolumn{2}{|l|}{ Admissions } & \multicolumn{2}{|c|}{1,009} & \multicolumn{2}{|c|}{879} & \multicolumn{2}{|c|}{815} & \multicolumn{2}{|c|}{657} & \multicolumn{2}{|c|}{3,365} \\
\hline \multirow[b]{2}{*}{ ECG } & Anterior ST changes & 453 & $44.9 \%$ & 383 & $43.6 \%$ & 365 & $44.8 \%$ & 337 & $51.3 \%$ & $|, 54|$ & $45.8 \%$ \\
\hline & Inferior ST changes & 497 & $49.3 \%$ & 455 & $51.8 \%$ & 407 & $49.9 \%$ & 281 & $42.8 \%$ & 1,642 & $48.8 \%$ \\
\hline \multicolumn{2}{|c|}{ Other ST changes } & 59 & $5.8 \%$ & 41 & $4.7 \%$ & 43 & $5.3 \%$ & 39 & $5.9 \%$ & 182 & $5.4 \%$ \\
\hline \multirow{5}{*}{ Killip Class } & I & 816 & $80.9 \%$ & 666 & $75.8 \%$ & 565 & $69.3 \%$ & 394 & $60.0 \%$ & 2,446 & $72.7 \%$ \\
\hline & II & 119 & $11.8 \%$ & 127 & $14.4 \%$ & 148 & $18.2 \%$ & 164 & $25.0 \%$ & 558 & $16.6 \%$ \\
\hline & III & 20 & $2.0 \%$ & 30 & $3.4 \%$ & 43 & $5.3 \%$ & 49 & $7.5 \%$ & 142 & $4.2 \%$ \\
\hline & IV & 10 & $1.0 \%$ & 8 & $0.9 \%$ & 13 & $1.6 \%$ & 15 & $2.3 \%$ & 46 & $1.4 \%$ \\
\hline & Missing & 44 & $4.4 \%$ & 48 & $5.5 \%$ & 46 & $5.6 \%$ & 35 & $5.3 \%$ & 173 & $5.1 \%$ \\
\hline \multirow{6}{*}{$\begin{array}{l}\text { Time Between } \\
\text { Onset of } \\
\text { Symptoms to } \\
\text { Arrival at } \\
\text { Hospital }\end{array}$} & $0-2$ hrs & 478 & $47.4 \%$ & 410 & $46.6 \%$ & 371 & $45.5 \%$ & 259 & $39.4 \%$ & 1,519 & $45.1 \%$ \\
\hline & $2-4$ hrs & 144 & $14.3 \%$ & 122 & $13.9 \%$ & 103 & $12.6 \%$ & 97 & $14.8 \%$ & 466 & $13.8 \%$ \\
\hline & 4-6 hrs & 60 & $5.9 \%$ & 56 & $6.4 \%$ & 45 & $5.5 \%$ & 32 & $4.9 \%$ & 193 & $5.7 \%$ \\
\hline & 6-12 hrs & 65 & $6.4 \%$ & 55 & $6.3 \%$ & 60 & $7.4 \%$ & 37 & $5.6 \%$ & 219 & $6.5 \%$ \\
\hline & $>12$ hrs & 128 & $12.7 \%$ & 108 & $12.3 \%$ & 104 & $12.8 \%$ & 80 & $12.2 \%$ & 420 & $12.5 \%$ \\
\hline & Missing & 134 & $13.3 \%$ & 128 & $14.6 \%$ & 132 & $16.2 \%$ & 152 & $23.1 \%$ & 548 & $16.3 \%$ \\
\hline \multirow{3}{*}{$\begin{array}{l}\text { Reperfusion } \\
\text { Therapy }\end{array}$} & Primary PTCA & 65 & $6.4 \%$ & 57 & $6.5 \%$ & 54 & $6.6 \%$ & 34 & $5.2 \%$ & 210 & $6.2 \%$ \\
\hline & Tlysis on Admit & 667 & $66.1 \%$ & 544 & $61.9 \%$ & 449 & $55.1 \%$ & 283 & $43.1 \%$ & 1,946 & $57.8 \%$ \\
\hline & None & 277 & $27.5 \%$ & 278 & $31.6 \%$ & 312 & $38.3 \%$ & 340 & $51.8 \%$ & 1,209 & $35.9 \%$ \\
\hline \multirow{5}{*}{$\begin{array}{l}\text { Time Between } \\
\text { Hospital } \\
\text { Arrival and } \\
\text { Thrombolysis }\end{array}$} & $<30$ mins & 359 & $53.8 \%$ & 263 & $48.3 \%$ & 171 & $38.1 \%$ & 109 & $38.5 \%$ & 904 & $46.5 \%$ \\
\hline & $30-40$ mins & 90 & $13.5 \%$ & 75 & $13.8 \%$ & 79 & $17.6 \%$ & 47 & $16.6 \%$ & 291 & $15.0 \%$ \\
\hline & $40-60$ mins & 87 & $13.0 \%$ & 99 & $18.2 \%$ & 85 & $18.9 \%$ & 55 & $19.4 \%$ & 326 & $16.8 \%$ \\
\hline & $>60$ mins & 105 & $15.7 \%$ & 86 & $15.8 \%$ & 83 & $18.5 \%$ & 67 & $23.7 \%$ & 342 & $17.6 \%$ \\
\hline & Missing & 26 & $3.9 \%$ & 21 & $3.9 \%$ & 31 & $6.9 \%$ & 5 & $1.8 \%$ & 83 & $4.3 \%$ \\
\hline \multirow{2}{*}{$\begin{array}{l}\text { Adverse } \\
\text { Events }\end{array}$} & Stroke & 2 & $0.2 \%$ & 4 & $0.5 \%$ & 4 & $0.5 \%$ & 6 & $0.9 \%$ & 16 & $0.5 \%$ \\
\hline & Major Bleed & 7 & $0.7 \%$ & 9 & $1.0 \%$ & 15 & $1.8 \%$ & 18 & $2.7 \%$ & 49 & $1.5 \%$ \\
\hline \multirow{2}{*}{ Death } & 48 hrs & 4 & $0.4 \%$ & 8 & $0.9 \%$ & 20 & $2.5 \%$ & 42 & $6.4 \%$ & 74 & $2.2 \%$ \\
\hline & 24 hrs & 2 & $0.2 \%$ & 3 & $0.3 \%$ & 12 & $1.5 \%$ & 18 & $2.7 \%$ & 35 & $1.0 \%$ \\
\hline
\end{tabular}

\section{Figure 5}

Use of Reperfusion Therapy in Men with ST Elevation Acute Myocardial Infarction in Canada, January I, 200 I to December 3 I, 200 I. Source: FASTRAK ${ }^{\circledR}$ I I Clinical Registry, 200 I

Age is often used as a surrogate for menopausal status, making it difficult to differentiate conditions that may be due to biological changes from those that may be attributed to other factors.
- Investigate alternative combinations and dosing of hormone therapy, in light of known risks and benefits, with respect to treatment of menopausal symptoms and longterm outcomes. 
- Investigate non-pharmacological alternatives (risks and benefits) for the treatment of menopausal symptoms, particularly those alternatives already in common use.

- Educate health care practitioners and women about the risks and effective treatments related toCVD so that women may present for treatment more quickly and receive the most effective therapies.

- Investigate the use of ovarian hormones to augment the effect of antidepressants in menopausal women.

\section{Note}

Views expressed in this report do not necessarily represent the views of the Canadian Population Health Initiative, the Canadian Institute for Health Information or Health Canada.

\section{References}

I. WHO Scientific Group on Research on the Menopause in the 1990s. WHO Technical Report Series. Geneva, Switzerland: WHO 1996.

2. North American Menopause Society: Clinical challenges of perimenopause: consensus opinion of the North American Menopause Society. Menopause 2000, 7:5-13.

3. Contestabile E, Derzko C: Canadian consensus on menopause and perimenopause. J Obstet Gynaecol Can 200I, 23(9):836-84I.

4. Woods NF, Mitchell ES: Patterns of depressed mood in midlife women: observations from the Seattle Midlife Women's Health Study. Res Nurs Health 1996, 19: I I I-I23.

5. McKinlay SM, Brambilla DJ, Posner JG: The normal menopausal transition. Maturitas 1992, 14:103-115.

6. Kaufert P, Gilbert P, Tate R: The Manitoba project: a reexamination of the link between menopause and depression in mid-aged women. Maturitas 1992, I4:|43-I55.

7. Dennerstein L, Dudley EC, Hopper JL, Guthrie JR, Burger HG: A prospective population-based study of menopausal symptoms. Obstet Gynecol 2000, 96:35I-358.

8. Obermeyer CM: Menopause across cultures: a review of the evidence. Menopause 2000, 7:184-192.

9. MacLennan A, Lester S, Moore V: Oral oestrogen replacement therapy versus placebo for hot flushes (Cochrane Review). In: The Cochrane Library Issue 2 Oxford: Update Software; 2002.

10. Barrett-Connor E, Stuenkel CA: Hormone replacement therapy (HRT): risks and benefits. Int JEpidemiol 200I, 30:423-426.

II. Neugarten BL, Kraines RJ: Menopausal symptoms in women of various ages. Psychosom Med 1965, 7:266-273.

12. Schmidt PJ, Rubinow DR: Menopause-related affective disorder: a justification for further study. AmJ Psychiatry |99|, I 48:844-852.

13. Schmidt PJ, Roca CA, Bloch M, et al:: The perimenopause and affective disorders. Sem Reprod Endocrinol 1997, 15:9|-100.

14. Dennerstein L, Smith AMA, Morse C: Psychological well-being, mid-life and the menopause. Maturitas 1994, 20: I-I I.

15. Hunter M: The south-east longitudinal study of the climacteric and postmenopause. Maturitas 1992, 14:143-155.

16. Avis NE, Brambilla D, McKinlay SM, et al.: A longitudinal analysis of the association between menopause and depression: results from the Massachusetts Women's Health Study. Ann Epidemiol 1994, 41:214-220.

17. Novaes C, Almeida OP: Premenstrual syndrome and psychiatric morbidity at the menopause. JPsychosom Obstet Gynecol 1999 20:56-57.

18. Novaes C, Almeida OP, de Melo NR: Mental health among perimenopausal women attending a menopause clinic: possible association with premenstrual syndrome? Climacteric 1998 I:264-270

19. McKinlay SM, Jefferys M: The menopausal syndrome. Br J Prev Soc Med 1974, 28:108-115.
20. Charney DA, Dara A: The psychoendocrinology of menopause in cross-cultural perspective. Transcultural Psychiatric Research Review 1996, 33(4):413-434.

2I. Burt VK, Altschuler LL, Rasgon N: Depressive symptoms in the perimenopause: prevalence, assessment, and guideline for treatment. Harvard Rev Psychiatry 1998, 6(3): | 2 |- 132.

22. Stewart DE, Boydell K: Psychologic distress during menopause: associations across the reproductive life cycle. Int J Psychiatry Med 1993, 23:57-62

23. Woods NF, Mitchell ES: Patterns of depressed mood in midlife women: observations from the Seattle Midlife Women's Health Study. Res Nurs Health 1996, 19: I II-I23.

24. Robinson GE: Cross-cultural aspects of menopause. J Nerv Ment Dis 1996, 184:453-458.

25. Harlow BL, Cohen LE, Otto MW, et al.: Prevalence and predictors of depressive symptoms in older premenopausal women. Arch Gen Psychiatry 1999, 56:4 I8-424.

26. Ditkoff EC, Crary WG, Cristo M, et al.: Estrogen improves psychological function in asymptomatic postmenopausal women. Obstet Gynecol I991, 78:991-995.

27. Schmidt PJ, Nieman L, Danaceau MA, Tobin MB, Roca CA, Murphy JH, Rubinow DR: Estrogen replacement in perimenopause related depression: a preliminary report. Am J Obstet Gynecol 2000, | 83:4|4-420

28. Soares CN, Almeida OP, Joffe H, Cohen LS: Efficacy of estradiol for the treatment of depressive disorders in perimenopausal women: a double-blind, randomized, placebo-controlled trial. Arch Gen Psychiatry 200I, 58:529-534.

29. Zweifel JE, O'Brien WH: A meta-analysis of the effect of hormone replacement therapy upon depressed mood. Psychoneuroendocrinology 1997, 22: 189-2।2

30. Schmidt PJ, Nieman L, Danaceau MA, et al.: Estrogen replacement in perimenopause-related depression: a preliminary report. Am J Obstet Gynecol 2000, 183:4|4-420.

3I. Klaiber EL, Broverman DM, Vogel W, et al.: Individual differences in changes in mood and platelet monoamine oxidase (MAO) activity during hormonal replacement therapy in menopausal women. Psychoneuroendocrinology 1996, 21:575-592.

32. Shapira B, Eppenheim G, Zohar J, et al.: Lack of efficacy of estrogen supplementation to imipramine in resistant female depressives. Biol Psychiatry 1985, 20:576-579.

33. Schneider LS, Small CW, Hamilton SH: Estrogen replacement and response to fluoxetine in a multi-center geriatric depression trial. Am J Geriatr Psychiatry 1997, 5:97-106.

34. Robinson GE, Stirtzinger R: Psychoeducational program and support groups at transition to menopause:. In: A clinician's guide to menopause Edited by: Stewart DE, Robinson GE. Washington DC: American Psychiatric Press Inc; 1997:165-179.

35. Taylor M: Botanicals: medicines and menopause. Clin Obstet Gynecol 200I, 44(4):853-863.

36. Liu J, Burdette JE, Xu H, Gu C, van Breemen RB, Bhat KPL, Booth N Constantinou Al, Pezzuto JM, Fong HHS, et al.: Evaluation of estrogenic activity of plant extracts for the potential treatment of menopausal symptoms. J Agric Food Chem 200I, 49:2472-2479.

37. Wijma K, Melin A, Nedstrand E, Hammar M: Treatment of menopausal symptoms with applied relaxation: a pilot study. J Behav Ther Exp Psychiatry 1997, 28:25I-26I.

38. Freedman RR, Woodward S: Behavioral treatment of menopausal hot flushes: evaluation by ambulatory monitoring. $\mathrm{Am} J$ Obstet Gynecol 1991, 167:436-439.

39. Leonetti HB, Longo S, Anasti JN: Transdermal progesterone cream for vasomotor symptoms and postmenopausal bone loss. Obstet Gynecol 1999, 94:225-228.

40. Grady D, Gebretsadik T, Kerlikowske K, Ernster V, Petitti D: Hormone replacement therapy and endometrial cancer risk: a meta-analysis. Obstet Gynecol 1995, 85:304-313.

4I. Nelson HD, Humphrey LL, Nygren P, Teutsch SM, Allan JD: Postmenopausal hormone replacement therapy: scientific review. JAMA 2002, 288:872-88।.

42. Writing Group for the Women's Health Initiative Investigators: Risks and benefits of estrogen plus progestin in healthy postmenopausal women: principal results from the Women's Health Initiative randomized controlled trial. JAMA 2002, 288:32 I-333.

43. Society of Obstetricians and Gynaecologists of Canada: Press Release: SOGC cautions women not to overreact to US study. SOGC Press Release 2002. 
44. American College of Obstetricians and Gynecologists: Statement on the estrogen plus progestin trial of the Women's Health Initiative. ACOG News Release . July 9, 2002

45. North American Menopause Society: Amended Report from the NAMS Advisory Panel on Postmenopausal Hormone Therapy. North American Menopause Society Advisory Panel 2002. October 6, 2002

46. U.S. Preventive Services Task Force: Postmenopausal hormone replacement therapy for the primary prevention of chronic conditions: recommendations and rationale. Ann Intern Med 2002, I 37( I 0):834-839.

47. Wathen CN, Feig DS, Feightner JW, Abramson B, Cheung A: Hormone replacement therapy for the primary prevention of chronic disease: recommendation statement by the Canadian Task Force on Preventive Health Care. CMAJ Canadian Medical Association Journal. May II, 2004

48. Rapp SR, Espeland MA, Shumaker SA, Henderson VW, Brunner RL, Manson JE, Gass ML, Stefanick ML, Lane DS, Hays J, Johnson KC, Coker LH, Dailey M, Bowen D, WHIMS Investigators: Effect of estrogen plus progestin on global cognitive function in postmenopausal women: the Women's Health Initiative Memory Study: a randomized controlled trial. JAMA 2003 , 289(20):2663-2672.

49. Shumaker SA, Legault C, Thal L, Wallace RB, Ockene JK, Hendrix SL, Jones BN 3rd, Assaf AR, Jackson RD, Kotchen JM, WassertheilSmoller S, Wactawski-Wende J, WHIMS Investigators: Estrogen plus progestin and the incidence of dementia and mild cognitive impairment in postmenopausal women: the Women's Health Initiative Memory Study: a randomized controlled trial. JAMA 2003, 289(20):265I-2662

50. Hays J, Ockene JK, Brunner RL, Kotchen JM, Manson JE, Patterson RE, Aragaki AK, Shumaker SA, Brzyski RG, LaCroix AZ, Granek IA, Valanis BG, Women's Health Initiative Investigators: Effects of estrogen plus progestin on health-related quality of life. $N \mathrm{Engl} J$ Med 2003, 348(19): 1839-1854.

5I. Tenenhouse A, Joseph L, Kreiger N, et al.: Estimation of the prevalence of low bone density in Canadian women and men using a population-specific DXA reference standard: the Canadian Multicentre Osteoporosis Study (CaMos). Osteoporos Int 2000, I I :897-904

52. Melton LJ, Chrischilles EA, Cooper C, Lane AW, Riggs BL: Perspective: How many women have osteoporosis? J Bone Miner Res 1992, 7:1005-1010.

53. Cooper C, Atkinson EJ, Jacobsen SJ, O'Fallon WM, Melton LJ: Population-based study of survival after osteoporotic fractures. Am J Epidemiol 1993, I37: 1001-1005.

54. World Health Organization: Guidelines for preclinical evaluation and clinical trials in osteoporosis. Geneva: WHO 1998:59.

55. Heart and Stroke Foundation of Canada: Heart disease and stroke in Canada. Statistics Canada, Health Canada, Heart and Stroke Foundation of Canada. Ottawa 1997.

56. Heart and Stroke Foundation of Canada: The changing face of heart disease and stroke in Canada. Ottawa 1999.

57. Smuraskawa LT, Alexandrov AV, Bladin CF, Norris JW: Costs of acute stroke care in Toronto, Canada. Stroke 1994, 25: |628-|63|

58. Holroyd-Leduc JM, Kapral MK, Austin P, Tu JV: Sex differences and similarities in the management and outcomes of stroke patients. Stroke 2000, 3 I: 1833-1837.

59. Kapral MK, Redelmeier DA: Carotid endarterectomy for women and men. J Women's Health Gender-Based Med 2000, 9: I-8.

60. Hochman JS, Tamis JE, Thompson TD, et al.: Sex, clinical presentation and outcome in patients with acute coronary syndromes. N Engl J Med 2000, 341:226-232.

6I. Zucker DR, Griffith JL, Beshansky JR, Selker HP: Presentations of acute myocardial infarction in men and women. J Gen Intern Med 1997, I 2:79-87

62. Mosca L, Grundy SM, Judelson D, et al.: Guide to preventive car diology for women. Circulation 1999, 99:2480-2484.

63. Mosca L, Manson JE, Sutherland SE, et al.: Cardiovascular disease in women: a statement for healthcare professionals from the American Heart Association. Circulation 1997, 96:2468-2482.

64. Steingart RM, Packer $M$, Hamm $P$, et al.: Sex differences in the management of coronary artery disease. N Engl ] Med 199|, 325:226-230.
65. Schulman KA, Berlin JA, Harless $W$, et al: The effect of race and sex on physicians' recommendations for cardiac catheterization. N Engl J Med 1999, 340:618-626.

66. Roger VL, Farkouh ME, Weston SA, et al.: Sex differences in evaluation and outcome of unstable angina. JAMA 2000, 283:646-652

67. CQIN Investigators: Low incidence of assessment and modification of risk factors in acute care patients at high risk for cardiovascular events, particularly among females and the elderly. Am J Cardiol 1995, 76:570-573.

68. McLaughlin TJ, Soumerai SB, Willison DJ, et al.: Adherence to national guidelines for drug treatment of suspected acute myocardial infarction. Arch Intern Med 1996, I 56:799-805

69. Pashos CL, Normand ST, Garfinkle JB, Newhouse JP, Epstein AM, McNeil BJ: Trends in the use of drug therapies in patients with acute myocardial infarction: 1988 to 1992. J Am Coll Cardiol 1994, 23:1023-1030.

70. Tsuyuki RT, Gill S, Hilton JD: Patterns of practice analysis for acute myocardial infarction. Can J Cardiol 1994, I 0:891-896.

7I. Stafford RS, Blumenthal D, Pasternak RC: Variations in cholesterol management practices of U.S. physicians. J Am Coll Cardiol 1997, 29:139-146.

72. Yusuf S, Peto R, Lewis J, Colling R, Seight R: Beta blockade during and after myocardial infarction: an overview of the randomized trials. Prog Cardiovasc Dis 1995, 27:335-37I.

73. Fibrinolytic Therapy Trialists' (FTT) Collaborative Group: Indications for fibrinolytic therapy in suspected acute myocardial infarction: collaborative overview of early mortality and major morbidity results from all randomised trials of more than 1000 patients. Lancet 1994, 343:3 I I-322.

74. ISIS-2 (Second International Study of Infarct Survival) Collaborative Group: Randomized trial of intravenous streptokinase, oral aspirin, both, or neither among 17,187 cases of suspected acute myocardial infarction. Lancet 1988, 2:349-356.

75. Haddad H, Searles G, Gillis A: The management of patients who have suffered an acute myocardial infarction in a tertiary care centre. Can J Cardiol 200I, I7:179-I83.

76. Tu JV, Austin P, Rochon P, Zhang Hua: Secondary prevention after acute myocardial infarction, congestive heart failure, and coronary artery bypass graft surgery in Ontario. In: Cardiovascular health and services in Ontario: an ICES atlas. Toronto: Institute for Clinical Evaluative Sciences 1999:199-238.

77. Clarke KW, Gray D, Keating NA, Hampton JR: Do women with acute myocardial infarction receive the same treatment as men? Br Med / 1994, 309:563-566.

78. Schwartz LM, Fisher ES, Tosteson NA, et al.: Treatment and health outcomes of women and men in a cohort with coronary artery disease. Arch Intern Med I997, I 57:|545-I55I.

79. Jackevicius CA, Anderson GM, Leiter L, Tu JV: Use of the statins in patients after acute myocardial infarction: Does evidence change practice? Arch Intern Med 200I, I6I:I83-188.

80. Vaccarino V, Chen YT, Wang Y, Radford MJ, Krumholz HM: Sex differences in the clinical care and outcomes of congestive heart failure in the elderly. Am Heart J 1999, I 38:835-842.

81. Luzier $A B$, DiTusa $L$ : Underutilization of $A C E$ inhibitors in heart failure. Pharmacoth 1999, 19:1296-1307.

82. Clinical Quality Improvement Network: Thromboembolic prophylaxis in $\mathbf{3 5 7 5}$ hospitalized patients with atrial fibrillation. Can J Cardiol 1998, 14:695-702. 